CuPAUAM 23, 1996, pp. 9-36

\title{
MONTAJE Y FUNCIONES DEL LABORATORIO DE CONSERVACIÓN Y RESTAURACIÓN EN UN MUSEO DE ARQUEOLOGÍA
}

\author{
CARMelo FernáNDEZ IBÁÑez \\ Museo Arqueológico. Palencia
}

\section{Resumen}

En la actualidad cualquier centro museológico no debe, o al menos no deberia carecer de un laboratorio bien equipado, donde poder llevar a cabo de una manera completa y eficaz cualquier labor de Conservación y/o Restauración de sus fondos. Se trata en definitiva de solventar los problemas más acuciantes que presentan los Bienes culturales (BB.CC.) de carácter mueble, y con ello, desarrollar una de las facetas fundamentales para los objetos custodiados. Esto es, la ineludible e inminente huella del tiempo, traducida de forma material en los más diversos tipos de alteración fisico-química.

Hoy abordaremos aquí el caso concreto de un museo arqueológico. Se describen y/o enumeran las diferentes áreas necesarias en un servicio de Conservación y Restauración, así como los productos y la maquinaria que es imprescindible. Distribución, montaje y caracteristicas de su puesta en marcha. También se observa el trabajo diario de los profesionales, desde todo tipo de responsabilidades, problemática y registro en las diferentes materias y objetos, hasta los peligros inminentes debidos a los productos que es necesario utilizar. Finalmente, se realizan unas reflexiones acerca de la didáctica cara al público, sobre las técnicas de Conservación y Restauración empleadas en estas siempre dificiles y mal conocidas actividades.

\section{INTRODUCCIÓN}

La Conservación y la Restauración pueden considerarse como jóvenes disciplinas en constante desarrollo. Si bien algo diferentes en cuanto a concepto y método, son necesariamente complementarias en la mayoría de los casos ya que nacen de un tronco común, corren paralelas en su desarrollo y persiguen un fin único, utópico por principio: la perdurabilidad e inalterabilidad en el tiempo de los llamados Bienes Culturales (BB.CC.) en el más extenso sentido del concepto. 
Llevan recorrido un corto aunque nutrido camino si las comparamos con otras disciplinas ya tradicionales, un camino cada vez más acelerado al ritmo de la imparable industrialización. Es indudable que existen lagunas y también que sus métodos y sobre todo las experiencias demostradas en muy distintos puntos geográficos, no siempre quedan convenientemente reflejadas en publicaciones especializadas. Algunas áreas de especialización apenas cuentan con líneas impresas, quizás por tratar temas centrados en aspectos que a priori pueden parecer asumidos o superados y sin embargo es una clara equivocación y el texto que hoy presentamos constituye una buena prueba de ello. Debemos constatar que sobre el tema de la instalación y montaje de laboratorios existen algunos artículos de corta extensión tratando el tema superficialmente, y aportando consejos de carácter general (Daifuku, 1979) (Hodges, 1979) (Organ, 1968 y 1987) (Pinllla Pinilla, 1982) (Slabczynski, 1964). Por nuestra parte durante varios años hemos ido contribuyendo con nuestra experiencia a este vacío bibliográfico en España (FernáNDEZ IBáÑEZ, 1986a, 1988, 1993), aumentando de información las diferentes publicaciones hasta lograr estas páginas redactadas a lo largo de los últimos siete años.

También hemos tenido en cuenta que el tema que nos proponemos desarrollar plantea un serio problema a quienes hoy preparan oposiciones a museos, tanto conservadores como sobre todo restauradores. Normalmente suele tratarse de un tema que los tribunales suelen integrar, mas los aspirantes se hallan con serios problemas en su preparación ya que los libros de museología nunca reflejan las características de los laboratorios de conservación y restauración. Este artículo si no como fuente directa de estudio sí al menos puede resultar un punto de partida.

Además no todos los centros museológicos cuentan con un laboratorio adecuado y menos aún de las características que aquí describimos. Y sin embargo si algún día tienen la posibilidad -fundamentalmente económica- de acometer su montaje, esperamos que el técnico encargado de tal labor pueda apoyarse en las experiencias que aquí aportamos. No queremos decir con esto que ofrezcamos la solución a todos los problemas, puesto que cada lugar es único, con necesidades y obstáculos propios que no podemos en modo alguno generalizar. Desde el material almacenado hasta los metros cuadrados disponibles, presuponiendo el ya citado desahogo económico, en cada caso específico deberemos evaluar convenientemente el binomio necesidad-disponibilidad, aunque la balanza tienda más a inclinarse en favor de las necesidades que de la disponibilidad de cubrirlas.

Pero no desearíamos en ningún momento incitar al desaliento. De hecho, lo que aquí nos proponemos desarrollar supone toda una serie de experiencias profesionales totalmente empíricas, en torno al montaje y equipamiento de cuatro laboratorios. Así como reflexiones sobre el montaje y desarrollo de laboratorios con especialidad en Conservación y Restauración para museos de arqueología que, siempre atendiendo a las posibilidades de que disponíamos en cada caso, han podido llevarse a cabo desarrollando posteriormente una eficiente labor. Aunque lo óptimo es hoy por hoy casi imposible de conseguir, la profesionalidad y el rigor que se ponga en la empresa podrán dar unos resultados cuyos índices positivos superen a los problemas aparentemente difíciles de resolver con los que, no obstante, debemos convivir casi a diario. 


\section{IMPORTANCIA DE LA CONSERVACIÓN EN NUESTROS MUSEOS}

Hace ya algún tiempo y en una publicación donde analizábamos aspectos concretos sobre la Conservación y la Restauración en los museos (FERNÁNDEz IBáÑez, 1987, 671), explicábamos y representábamos mediante un sencillo esquema de trinomio, cómo el fin principal de estos centros es el cuidado, custodia y estudio de los Bienes Culturales en general. Esto era:

\section{CONSERVACIÓN Y RESTAURACIÓN + INVESTIGACIÓN = EXPOSICIÓN}

Con ello no pretendíamos en absoluto dejar en un segundo plano todas las demás facetas. Simplemente exponer que las dos últimas actividades enunciadas (investigación y exposición), contadas veces podemos desarrollarlas satisfactoriamente sin las restantes; un ejemplo lo ilustrará mejor. Generalmente todos los objetos procedentes de una excavación arqueológica no suelen aparecer con el mismo grado de conservación. Bien sean huesos, cerámicas o metales entre otros muchos, las alteraciones suelen ser frecuentes: pulverulencia, grietas, roturas, oxidaciones, alteración de pinturas o engobes, etc... Estos procesos suelen verse acelerados en los lugares de almacenamiento, y a veces de forma involuntaria durante otro tipo de tareas científicas previas como dibujo, fotografía e investigación. Dichas alteraciones generan para desdicha del estudioso una ocultación cuando no la pérdida de datos (atributos) no todos recuperables, debido a la inherente desaparición de materia que indefectiblemente altera a los objetos y que es la portadora de la citada información.

Por ley natural todo tiene un principio y un ineludible fin tarde o temprano. Este hecho constatable en nuestros actuales museos con respecto a los objetos ingresados de antiguo, es una de las principales facetas aún por abordar de forma integral. El primer paso sería frenar su inestabilidad; el siguiente -y en el que aún estamos a tiempo en muchos casos-, la intervención inmediata de las piezas que de manera continua siguen almacenándose. Comprendería desde las adquisiciones y donaciones, hasta -y sobre todo- los ingentes lotes de variopintos objetos que anualmente se extraen en las diferentes campanas de excavación.

La intervención inmediata supone o debería suponer el tratamiento de objetos y a la vez la extracción del volumen más completo posible de información, es decir, la investigación propiamente dicha. Datos, que por otra parte podrán ser de nuevo reelaborados en el futuro por otros investigadores. De aquí se deriva el último aspecto del trinomio anterior, y es la exposición de los resultados. La muestra al público de los susodichos resultados elaborados e interpretados convenientemente permiten mostrar cómo fueron y cómo se llegaron a desarrollar las diferentes culturas (en el sentido más amplio del concepto pero limitada la información fundamentalmente al hecho material), de las sociedades motivo de exposición y estudio (Fernández Martínez, 1989, 85 y ss.).

La conservación por lo tanto deberá ser un deber prioritario en todo museo, y un derecho que de por sí tienen adquirido los objetos. Es ya un tópico y no por ello menos cierto, que los diferentes Bienes Culturales custodiados suponen nuestra Herencia Histórica, y que tales Bienes son de propiedad única y exclusivamente pública. Esta reflexión nos lleva a un 
importante punto a tratar y es el de la concienciación social. No están aún asumidos por parte de la sociedad en general los dos puntos antes enunciados, prueba inequívoca es que un cierto sector encuentra placer en su destrucción. Pocas veces la sociedad exige algo de ellos, comenzando por su conservación hasta su conveniente explicación y adecuada exposición.

Las noticias sobre destrucciones, robos, mutilaciones o erróneas manipulaciones se multiplican en la prensa diaria, pero tras la denuncia de inmediato se pasa al más absoluto de los olvidos. La educación ha sido y será siempre el principal sistema para el desarrollo y progreso de cualquier sociedad: "El pueblo que no conoce su bistoria está condenado a repetirla" reza la vieja sentencia. De él emanan otra serie de reflexiones que no es momento de relatar. Si alguna vez lo conseguimos habremos logrado indudablemente lo más difícil.

\section{LA ELECCIÓN DEL EMPLAZAMIENTO}

Entraremos ya de lleno en materia haciendo referencia al primer problema al que se enfrentan nuestros museos, el del emplazamiento. Resulta una práctica habitual que nuestros museos se instalen aprovechando un edificio antiguo. Aunque la mayoría de las veces es creencia común que se encuentra convenientemente acondicionado, lo cierto es que incluso reorganizando o reconstruyendo su interior, la estructura general de la construcción resulta difícilmente adaptable a las necesidades más actuales de la museología. Así nos encontramos con que los itinerarios son a duras penas coherentes (o que no pueden llevarse a cabo de forma coherente), zonas de almacenamiento poco aptas, etc... El mismo problema se nos presenta respecto a las áreas de servicio, y dentro de ellas los lugares destinados al tema que nos compete, los laboratorios de Conservación y Restauración, antiguamente llamados talleres.

Pocas veces el edificio museístico puede disponer del local indispensable y sobre todo adecuado para este tipo de laboratorio. Las razones son múltiples y las obviaremos hoy aquí para no salirnos del tema tratado. Lo verdaderamente importante será enumerar las características con las que debería contar un lugar como éste. En primer lugar el espacio disponible para su instalación deberá ser lo más espacioso que nos sea posible, aunque en un principio y debido a momentáneos impedimentos de espacio contemos con un pequeño local. Con respecto a esto último deberemos tener en cuenta que se trata de un servicio en constante expansión debido fundamentalmente a dos motivos. Los tratamientos aplicados a los objetos van constantemente evolucionando al ritmo de las investigaciones, conllevando un aumento y mejora de maquinaria y productos, y la expansión lógica del laboratorio mediante la adquisición de un equipamiento tan básico como absolutamente necesario, de materiales que -en términos administrativos- sería tanto el fungible como el inventariable. Otro handicap a tener en cuenta y que resulta directamente proporcional al tamaño del local, es el almacenamiento de piezas a restaurar en un futuro, y las dimensiones a veces demasiado grandes de objetos a intervenir, sobre todo si se trata de cuadros, retablos o imaginería. El reducido espacio disminuye ostensiblemente el campo de actuación -tanto para el objeto como para el profesional-, incidiendo de una manera directa en el resultado de su trabajo y el tiempo dedicado a su intervención. 
La situación en altura del laboratorio es otro de los puntos importantes. Esto mismo también es extensible en el momento de la elección del lugar donde deberá instalarse el laboratorio de Conservación y Restauración. Generalmente antaño venía siendo común destinarlo al cubículo más reducido, menos iluminado y a veces hasta insalubre ubicándolo poco más o menos que en el sótano del edificio. Sin pretender que nuestra postura sea en absoluto irreflexiva e intolerante, de ninguna de las maneras deberemos admitir una imposición tan aleatoria como imprudente. Diversas serán las motivaciones. La salud de los profesionales será lo primero a valorar, la humedad y el calor, la necesidad de ventilación, la seguridad de los objetos, luz en abundancia... y un largo etcétera son ya de por sí motivos suficientes. Nunca suele haber duda o haber problemas similares a la hora de escoger los recintos para biblioteca, secretaría o dirección. Por contra también conocemos de cerca situaciones bien contrarias a lo que venimos diciendo.

Escogeremos preferentemente un lugar alto en el edificio y bien orientado, y si se encuentra cercano o junto al tejado aún mejor. Si es así no olvidaremos el aislamiento contra el frío del invierno y el calor estival. El primero lo paliaremos con calefacción central regulable así como aislamientos térmicos en techos y paredes si fuera necesario. Estos aislamientos procuraremos así mismo nos sirvan en verano para con los rigores del calor, que suelen ser especialmente intensos en determinados puntos del edificio según la situación geográfica de la ciudad. Creemos no estar exagerando si aseguramos que en estos laboratorios es necesario instalar aire acondicionado, ya que resulta una auténtica tortura trabajar con exceso de frío o bien de calor. Por otra parte, ciertos productos como pueden ser por ejemplo adhesivos (epoxídicos o nitrocelulósicos) y disolventes (cetonas, alcoholes...), se comportan ante tales extremos térmicos de forma dispar y hasta cierto punto imprevisible. La tolerancia de los vapores de ciertas sustancias químicas puede llegar a la peligrosidad. No obstante respecto a este último punto, un frigorífico de las más simples características puede ser de ayuda con el fin de paliar este posible problema.

La situación en alto del laboratorio nos permitirá además disponer de abundante luz cenital (más la artificial, de la cual hablaremos más adelante), muy importante para un trabajo tan minucioso como el que allí se desarrolla. Esta situación además nos permitirá más fácilmente y con ausencia de complicaciones estructurales y materiales, instalar la salida de gases insalubres. Estos vienen inexorablemente generados por la aplicación a las obras de arte y demás objetos de productos más o menos tóxicos aplicados en campana de protección, por la cual salen expelidos a la atmósfera mediante un tubo acoplado a un extractor. Con respecto a esta toxicidad, nunca es expulsado al exterior una cantidad tal de producto nocivo en forma de vapor como para hacer peligrar la vida de los inmuebles cercanos, ya que los gases de inmediato se diluyen en el oxígeno ambiental y pierden su poder tóxico. El caso contrario y bien distinto sería el de una atmósfera industrial. El óxido de etileno utilizado en las más modernas cámaras aislantes de desinsectación es un gas sumamente peligroso pero que una vez utilizado no se expulsa al exterior sino que se almacena de nuevo. Naturalmente para instalar y utilizar este tipo de gas así como un tipo de maquinaria precisa y concreta, indefectiblemente nos tendremos que atener rigurosamente a las normas de seguridad y salubridad propuestas por el Ministerio de Industria y Energía. Este deberá dar el visto bueno a su puesta en marcha. 
Siguiendo con necesidades y prioridades para alojar el laboratorio ideal, sería conveniente que estuviese ubicado junto a las áreas de dibujo y fotografía; si es que no cuenta con un rincón para este último importante menester. Fundamentalmente por la documentación de los objetos tratados desde el punto de vista de la arqueología, la historia y la conservación que como vimos es tarea entre las primordiales en un museo. Aún mejor si los almacenes están cerca o bien comunicado con ellos mediante un montacargas, que además será de gran utilidad para el transporte de objetos a tratar en el local. Lo idóneo sería que dicho transporte recorriese de arriba a bajo todo el edificio recorriendo el mayor número de dependencias -tanto expositivas como de servicios- que fuese posible.

\section{EQUIPAMIENTO E INSTRUMENTAL IMPRESCINDIBLE: SU DISTRIBUCIÓN Y MONTAJE}

Las técnicas y los sistemas operativos en Conservación y Restauración han llegado a evolucionar considerablemente respecto a décadas anteriores, y día a día siguen avanzando al ritmo y al amparo de las diferentes ciencias y disciplinas que les sirven de apoyo. Es por ello que con el paso de los años se ha llegado a reunir un vasto stock comercial tanto instrumental como de productos. Si bien es verdad que no es necesario adquirir absolutamente todo, la verdad es que resultaría muy perjudicial carecer de lo imprescindible. Lo que verdaderamente cuenta en principio son los conocimientos del profesional y la correcta valoración de lo que las piezas a tratar requieran, en función de lo cual realizaremos la primera lista de adquisiciones (normalmente algo más de lo imprescindible), que por adelantado auguramos que por poco que sea resulta siempre larga. También se puede realizar por etapas según las necesidades y el dinero disponible hasta completar el total de las susodichas necesidades.

No deberemos caer nunca en el grave error de adquirir por el simple hecho de adquirir, tener por tener y almacenar. Muchas veces se suele aplicar el razonamiento absurdo de $s i$ los demás lo tienen, yo también. Dentro de esto mismo puede caber el hecho de la compra alternativa de aparatos por parte de dos o más centros si por ejemplo se diese el caso de altos costes económicos, y la siempre por todos conocida deficiencia económica. La interdisciplinariedad en los proyectos así como la colaboración y conocimientos compartidos generará un trabajo fluido, eficaz y rentable; tanto en el momento actual como cara al futuro.

Pero entrando ya de lleno en la enumeración y descripción de las partes fundamentales de un laboratorio, deberemos tener en cuenta que antes de realizar cualquier tipo de obra en él, sería necesario contar con un plano detallado de la habitación escogida.

Sobre él y una vez que tengamos construida una idea suficientemente clara de lo que necesitamos en función del material a conservar y fundamentalmente de las posibilidades económicas actuales y futuras, realizaremos un planteamiento general. Es una simple cuestión de sentido común. Dicho planteamiento estará basado en el máximo aprovechamiento del espacio disponible, teniendo siempre la predisposición de no convertirlo en algo parecido a un almacén donde el desenvolvimiento del operador sea dificultoso. Lo más correcto será al menos encontrar una relación equilibrada entre nuestras necesidades y posibilidades. 
- La iluminación del lugar de trabajo debería ser en su mayor parte de tipo solar. Naturalmente, esto requiere la existencia de amplios ventanales y una perfecta orientación del laboratorio, lo cual no siempre es posible, quizá incluso porque no se considera necesario en el momento de la ubicación y debemos solventar las deficiencias por otros medios. Con el fin de evitar zonas de penumbra o trabajar de noche, lo más adecuado son los tubos fluorescentes de luz-día, ya que aportan un grado de intensidad considerable; de todos modos, cada caso específico requerirá un mínimo y disposición de tubos diferente. Quizá se trate de reforzar lumínicamente zonas o ángulos concretos en un espacio amplio con pocas ventanas, un rincón poco accesible, determinados aparatos de trabajo.... En estos lugares necesitaremos al menos 1000 Lux de intensidad lumínica sobre todo si se realizan trabajos delicados.

Por muy diversos motivos, este punto es fundamental, tanto como una correcta identificación de alteraciones o la entonación más adecuada en una reintegración cromática. Por otra parte, no debemos olvidarnos de la salud visual del propio trabajador. El trabajo del restaurador resulta de por sí un duro ejercicio que con el paso del tiempo desemboca en una inevitable fatiga ocular, por lo que cualquier intento de mejorar las condiciones de trabajo, redundará a medio o largo plazo en una mejora de la calidad del mismo. Será imprescindible una intensidad mínima ambiental de 500 Lux.

Algo fundamental serán las tomas de corriente o enchufes, que deberán estar presentes en todas las paredes e inclusive a ser posible en el techo mediante raíles. Su número y distribución será algo bien estudiado ya que deberemos contar con cobertura eléctrica en todo lugar y circunstancia, ya que casi todos los aparatos funcionan a la red. Tendrán suficiente potencia, toma de tierra y estarán protegidos. Será posible desconectarlos desde el cuadro eléctrico que controle el suministro a todo el laboratorio.

- El abastecimiento de agua corriente es uno de los puntos fundamentales dado que aparte de las limpiezas, los tratamientos de conservación la mayoría de ellos van aplicados por vía húmeda. En este lugar aparte de agua corriente instalaremos uno o mejor varios grifos desde donde realizaremos las tomas de agua fría, caliente (para lo que es necesario contar con un calentador eléctrico mucho mejor que de gas, etc...). También una toma que pasando por las resinas cambiadoras de iones contenidas en el desmineralizador purifiquen los minerales en dicha agua. Si aún deseamos una depuración máxima podemos instalar un pequeño alambique mediante el cual la destilaremos. De todas formas el uso de este último accesorio no es estrictamente imprescindible. En esta misma línea sobre la obtención de agua pura, sino aún más extremadamente pura (ultrapureza) libre de iones, materia orgánica, partículas diversas y coloides, existen en el mercado pequeños y eficaces depuradores al efecto ${ }^{1}$. Su tamano es reducido y su mantenimiento sencillo mediante cartuchos intercambiables, aunque económicamente muy caro. Su campo de actuación se encuentra en base a la analítica cromatografía iónica, de absorción atómica, lavado de circuitos electrónicos, enzimología, etc... donde es necesaria este tipo de agua también denominada de grado reactivo. Aunque es factible de ser aplicada en nuestros trabajos su alto coste económico la hace dificilmente utilizable. De momento no supone problema alguno el no disponer de ella pues los

${ }^{1}$ Una marca comercial de reconocida efectividad puede ser Millipore Ibérica, S.A. (Av. Llano Castellano n² 13 , 28034-Madrid). 
mismos resultados que obtenemos para la aplicación de nuestros tratamientos pueden llegar a conseguirse con un simple desmineralizador..

En este lugar también será necesario disponer de escurridores para material vario de laboratorio, productos de limpieza y saneamiento, piletas con encimeras, desagües especialmente protegidos para que el vertido de residuos químicos inocuos no los ataque y disuelva, filtros si los productos vertidos así lo exigiesen, receptáculos bajos de almacenamiento, etc... Esta zona es aconsejable que se encuentre revestida de baldosines cerámicos.

- Una vez llegan a nuestro laboratorio los diferentes objetos serán imprescindibles grandes piletas de almacenamiento y desalación (con desagües protegidos contra materias que los llegasen a atascar), sobre todo para aquellos de grandes dimensiones como pueda ser un cañón. Estos receptáculos necesitarán a veces complicadas obras de fontanería, albañilería y electricidad dentro de un espacio obligatoriamente amplio. Para la cerámica también será necesario contar con piletas de obra o bien recipientes, mas no obstante su tamaño puede ser más reducido y ser fabricados en otro tipo de materia (plástico, aluminio...) (MARIN Baño Y ZaMBrano, 1995). En el caso de que tales voluminosos receptáculos contengan objetos de metal, deberían estar acondicionados para recibir los electrodos que unidos a un generador de corriente, puedan permitir la ejecución de una reducción de tipo electrolítico (NORTH, 1987, 223-227) (PeArSon, 1984, 97-99); o sea lo que sería una cuba. Así mismo también poder acoplar hélices para remover el agua y serpentines térmicos para calentarla, aislantes térmicos de tal manera que podamos efectuar desalaciones en los objetos de hierro (baño termostático) tan imprescindibles si deseamos su completa e imprescindible estabilidad físico-química. No deberemos olvidar en este último caso que la más perfecta limpieza del recipiente y sobre todo del serpentín es fundamental, dado que el Sulfito Alcalino (RINUY Y SCHWEIZER, 1982) que se utiliza en disolución afecta a esta última pieza.

Para desplazar de un lugar a otro objetos de gran peso -y como ejemplo podemos seguir utilizando un cañón o bien el cepo plúmbeo de un ancla romana-, será imprescindible la instalación de una grúa aérea movida mediante raíles y poleas. Lo que hace imprescindible que nuestro laboratorio sea de techo alto. La madera y demás elementos orgánicos, hasta su tratamiento definitivo conviene mantenerlos en cámaras frigoríficas a unos $5^{\circ} \mathrm{C}$. Los liofilizadores que actualmente nos proporcionan el mejor tratamiento estabilizador a la madera y el cuero arqueológicos, son instrumentos de trabajo con un cierto volumen (según tamaño de los objetos a tratar naturalmente) aunque nunca de gran tamaño, y deberemos preverlo también en la planificación inicial.

En este punto y al hilo de lo que acabamos de exponer, hemos de hacer obligada referencia a un sistema de impregnación mediante P.E.G. que está proporcionando excelentes resultados en el tratamiento de maderas empapadas. Nos referimos al "Tanque de Tratamiento de Maderas" construido en el Centre d'Investigacions Arqueològiques de Girona, en base a las experiencias de MurDOCH (1978). Dicho receptáculo cuyas medidas son de $4 \mathrm{x}$ $1 ' 5$ x 1 '5 mts. y 140 litros de volumen fabricado en acero inoxidable, cuenta con resistencias eléctricas, conducto del circulación para la solución consolidante, bomba de circulación, termómetro, aislante térmico oleoso, etc..., etc... Los objetos del pecio romano de Cala Clip I - entre otros más- probaron su eficacia con lo reducido de su tamaño (Jover, 1989, 53 y 1993, $80)$. 
Además deberemos contar con las cámaras para almacenar estas grandes piezas de madera, como pueden ser fragmentos de mástil, cuadernas o varias piezas unidas (fragmento de casco), etc... Cara a la amortización de estos grandes receptáculos que incluso sería factible utilizarlos para el tratamiento de los objetos más pesados sería más factible el instalarlos en un gran centro de restauración como pudiera ser un instituto a nivel nacional e inclusive regional, pero especializado en temas subacuáticos. El tamaño del instrumental no supone hoy por hoy límite alguno. Existen en el mercado liofilizadores de reducidas dimensiones para la conservación de objetos orgánicos de tamaño medio. Sin ser estos, se han logrado excelentes resultados en los tratamientos de estabilización para grandes piezas de madera empapada mediante PEG (Polietilenglicol) -cera sintética soluble en agua-(FranCo GonZẢLEZ y CASARES GONZÁLEZ, 1980, 62), utilizando un aparato muy parecido al desalador de hierro ya visto algunas líneas atrás.

No deberíamos clausurar este apartado sin hacer referencia algo más extensa al tratamiento de disolución de sales férricas, pero esta vez mediante -de momento- un costoso aparato: cerca de un millón de pesetas en el año 1990. Se basa en el poder reductor del plasma (gas ionizado) Hidrógeno/Metano según el investigador alemán que lo ha desarrollado y publicado recientemente (Veprek, 1990). Aunque de elevado precio, las experiencias han resultado satisfactorias sobre los veinte mil clavos que han sido utilizados como campo de pruebas. Razonablemente el descubridor de este tipo de reducción aconseja en aras de la mejor amortización y eficacia del ingenio, que su adquisición sea hecha por un gran centro o bien varios laboratorios en unión.

- Íntimamente unido a la seguridad física del propio trabajador, la ventilación será oțro de los puntos importantes. Los diferentes gases y olores que desprenden los productos utilizados en Conservación y Restauración por otra parte totalmente incompatibles con nuestro organismo deberán ser expulsados al exterior de modo prioritario. Se considera que la ventilación más adecuada para un laboratorio es de $10 \mathrm{~m}^{3}$ por persona. Como prevención contra posibles accidentes será conveniente instalar hélices extractoras colocadas en las ventanas. Su número variará, aunque siempre debería estar en proporción directa a la más rápida aireación del local, al crear entre todas ellas corrientes de aire suctoras. El estar emplazadas en un lugar alto puede ser un factor que beneficie y favorezca nuestra intención, de tal forma además que los productos expulsados no produzcan efectos secundarios. Pero ya dijimos que su rápida mezcla con el oxígeno neutraliza de forma inmediata posibles repercusiones.

- Como no existe la completa seguridad de que en los laboratorios de Conservación y Restauración no exista el riesgo de accidentes, deberían estar equipados al menos con extintores $^{2}$ y detectores de llama, térmicos o de humo, tanto en el área de trabajo como en el almacén variando en número según el tamaño de la habitación o el peligro inherente así

${ }^{2}$ Los fuegos se clasifican en cuatro clases: A. provocado por materiales combustibles, recomendándose no usar extintores de $\mathrm{CO}_{2}$. B. provocados por liquidos inflamables y no recomendándose utilizar extintores de agua. C. o provocados por descargas eléctricas y donde tampoco utilizaremos el ågua, y D. provocados por metales combustibles no recomendándose usar extintores de $\mathrm{CO}_{2}$. 
como también pulsadores de alarma. Lo más aconsejable es emplazar el detector o detectores en el techo y los extintores colgados de la pared, cerca del lugar o productos con mayor riesgo de explosión y/o inflamabilidad.

Este punto da pie a que hagamos referencia a todos aquellos aparatos que deberán formar parte del equipo necesario en cuanto a la seguridad del propio laboratorio, y del personal que en él trabaja. Tal y como ya vimos para el almacén, la madera ignífuga para la construcción de puertas y ventanas será de indudable necesidad en aquellos lugares donde no sean de P.V.C. por ejemplo. También, y en el caso extremo de producirse explosiones seguidas de un incendio, las paredes deberían estar convenientemente tratadas para que el fuego quedase allí retenido el mayor tiempo posible. De esta manera es posible que pudiésemos salvar el edificio o parte de él.

La necesidad de dotar al laboratorio de un botiquín de primeros auxilios convenientemente surtido, la experiencia de años ha demostrado de forma fehaciente su gran necesidad y utilidad. Serán imprescindibles: colirios oculares, gasa hidrófila, desinfectantes varios, analgésicos, productos para quemaduras, cinta adhesiva, etc... Recientemente y en base a la experiencia adquirida en la empresa privada, está demostrado ser a todas luces necesaria la instalación de duchas oculares y/o bien corporales en el caso de neutralizar accidentes de tipo químico. Las primeras son cubetas cuyos chorros de agua están dispuestos dentro de ellas de manera inversa a lo que suele ser común. Accionando el dispositivo correspondiente, los grifos lanzan sendos chorros acuosos directamente a nuestros ojos, neutralizando de manera total (pero momentánea) la agresión ${ }^{3}$. De inmediato acudiremos a un especialista.

Ciertos laboratorios acertadamente cuentan con departamentos independientes donde no solamente se almacenan los productos tóxicos que diariamente se manejan, sino que allí mismo se efectúan los tratamientos en vacío, aerografía -y todo lo que requiera un compresor-, trabajos con microabrasímetro, tornos, etc... Están aislados acústicamente además de otras medidas de seguridad, lo que garantiza un trabajo sin penosidad ni toxicidad (BELtrán LL.oRis, 1994, 399).

- De esta manera deberemos contar en primer lugar y de forma imprescindible con una o varias mesas a ser posible de diferentes tamaños, donde poder realizar el trabajo diario en función del tamaño del/los objeto/os a tratar. Serán de especiales dimensiones aquellas destinadas a soportar mosaicos, madera (esculturas, mobiliario, sarcófagos...), o bien pintura mural. Así mismo la altura de las mismas tendrá su importancia en función directa con la comodidad del trabajo. A veces el coste y/o dificultad que supone su construcción por encargo, se puede ver paliada -al menos de forma momentánea- por una simple tabla de dimensiones adecuadas sobre un par o más de soportes en bisagra (caballetes). La dificultad formal o de peso con respecto a la obra a intervenir necesitará del ingenio o sexto sentido del pro-

'La marca comercial BRAND de Alemania especializada en equipamiento para laboratorios químicos, cuentat en su stock con un pequeño y útil equipo para el lavado de ojos mediante un frasco-aplicador de $500 \mathrm{ml}$. fabricado en polipropileno. 
fesional, mediante el cual poder diseñar modelos que se ajusten a las necesidades de cada caso específico. Alguna de estas mesas pueden disponer de uno o varios grupos de armarios así como cajoneras complementarias, donde poder almacenar diverso material de tamaño reducido tan imprescindible y común en la profesión: escalpelos, pinceles, agujas, lijas, espátulas, recambios diversos, hipodérmicas, tijeras, etc..., etc... que luego veremos.

- En nuestro lugar habitual de trabajo necesitamos ineludiblemente varias líneas de estanterías, armarios y/o vitrinas en las cuales tener a mano los productos más usuales con los que trabajamos de continuo ${ }^{4}$. Las cantidades depositadas en este lugar deberán ser escasas para evitar riesgos innecesarios tales como emanaciones tóxicas, inflamabilidad, etc... o simplemente el hacinamiento, sobre todo en lo que respecta a disolventes y productos ácidos. Será en el almacén donde tengamos los depósitos-reserva contenidos en bidones de varios litros, cuya adquisición de esta manera resulta más económica. Por lo tanto este almacén no debería ubicarse demasiado lejos con el fin de que el abastecimiento (litro a litro por ejemplo) no resulte engorroso.

- Junto a todo ello se encuentra el instrumental mecánico que podríamos denominar más específicamente de limpieza mecánica y ópticos. Difícilmente podrán tales aparatos estar reunidos en un lugar determinado ya que debido a su tamaño, y estar destinados a funciones muy concretas a la vez que individualmente unidos a aparatos aquí enumerados, su distribución por nuestro laboratorio tiende a ser irregular. Dentro de lo que podría ser el primer grupo reuniríamos a los instrumentos abrasivos (microtaladros y tornos de protésico dental, microabrasímetros -chorro de arena-...), así como el tanque de ultrasonidos; el lápiz ultrasónico (cavitrón) (Mourey, 1987, 43) tanto por vía húmeda como el último modelo utilizable en seco (piezón).

- El grupo óptico lo componen todos aquellos aparatos compuestos por lentes de aumento y destinados a que entre otros quehaceres la limpieza sobre los objetos a intervenir sea llevada a cabo de una manera más profunda, segura y eficaz mediante la ampliación del tamaño de los objetos, o más bien, partes muy determinadas de ellos. Así contaremos en primer lugar con lupas binoculares y los siempre imprescindibles aunque -de nuevo- económicamente caros binoculares con equipo fotográfico incorporado ( $35 \mathrm{~mm}$., Polaroid...) y de vídeo si se desea, o bien las lupas con luz fluorescente. Desde el mayor de los objetos hasta la moneda de menor tamaño, necesitan indefectiblemente de un vehículo óptico que nos permita acceder lo más cómodamente y de manera segura hasta los recovecos más intrincados, a partir de lentes variadas en cuanto a sus aumentos. La información recogida mediante un aparato gráfico y las notas tomadas durante la observación de los procesos de alteración (estratigrafias de corrosión, productos resultantes...), serán de vital importancia no sólo para el más perfecto tratamiento, sino además para su registro, posibilidades en cuanto a la investigación, etc... y en definitiva su más correcta intervención.

+ Un sencillo y a la vez útil sistema contra posibles emanaciones de carácter ácido en este lugar es instalar entre los productos, pequeños recipientes de tapadera perforada que contengan Bicarbonato de Sodio con el fin de neutralizar los posibles vapores. 
— El secado de las diferentes materias que forman los objetos (cerámica, piedra...) y como paso fundamental en el tratamiento de los metales, será llevado a cabo mediante estufas. Se procurará escoger siempre las denominadas de Aire Regenerado o forzado (secadores de vidrio por ejemplo) ${ }^{5}$. En éstas y mediante un ventilador se introduce el aire ambiente en la cámara de secado. Aire que por supuesto será calentado en el interior a la temperatura que nosotros hayamos previamente seleccionado en el programador, y que después es eliminada al exterior por las salidas existentes al efecto. Este último efecto impide que la humedad eliminada del objeto por calentamiento no se condense a posteriori en el interior, produciendo de esta manera un efecto contrario al deseado y con posteriores problemas de índole varia. A veces y para un tipo muy específico de tratamiento son necesarios ciertos hornos que alcanzan temperaturas mayores con respecto a las estufas vistas anteriormente. Puede llegar a alcanzarse los $1100^{\circ}-1200^{\circ}$ con las llamadas muflas, de cuyos tamaños y niveles de temperatura existe una variada gama en el mercado. Últimamente hemos tenido constancia de la aparición en el mercado, un tipo de estufa que lleva incorporado una pequeña bomba de vacío. Creemos, de momento, que puede tener buena aplicación para nuestros fines de conservación.

- A estos habría que unir todos los instrumentos de pequeño tamaño que aun no siendo aparatos eléctricos su grupo conforma el voluminoso e imprescindible utillaje empleado día a día por los profesionales de la Conservación y Restauración así: escalpelos, agujas citológicas (cilíndricas y de lanceta), portaminas-lápices y brochas de fibra de vidrio, punzones (o lápices) de madera de naranjo, espátulas, instrumental odontológico vario, etc..., etc... No olvidaremos la balanza a ser posible de precisión, el peachímetro digital, conductivímetro para las desalaciones y a ser posible, un buen termómetro digital, todo ello con base a su probada y necesaria precisión. La toma de datos y las mediciones precisas harán por una parte más fiables los tratamientos y por ende más rigurosas las investigaciones. A este respecto debemos tener en cuenta que hoy día por ejemplo las balanzas de semiprecisión, los papeles reactivos de PH (papel tornasol), la prueba visual de cloruros (mediante ácido nítrico y óxido de plata) y el termómetro clínico convencional, son aparatos que si bien pueden seguir utilizándose, poseen un margen de error en sus mediciones que puede ser más o menos amplio según el caso. En nuestra profesión no es necesario un tipo de exactitud astronómica, pero sí lo más puntual y fiel que resulte posible dentro de unos parámetros fiables. No obstante y aunque a veces económicamente caro esta inversión deberá entenderse no como un lujo, sino más bien como bienes necesarios y amortizables; laboralmente hablando.

- La auténtica parafernalia de útiles varios y recipientes absolutamente necesarios desde todo punto de vista, haría interminable este apartado. Al igual que ya vimos en cuanto a criterios de Conservación y Restauración, partiendo de unos instrumentos básicos y comunes a todos los profesionales, nace toda una lista siempre extensa de necesidades que caracterizan individualmente a cada uno según sea el método de trabajo elegido, las necesidades de las materias alteradas o bien las técnicas operativas, así mangos de bisturí (de ciru-

'Con esto no queremos decir en absoluto que las denominadas de Aireación Natural no sean útiles y cumplan de forma perfecta su cometido. 
gía corporal y visual) con sus correspondientes hojas, agujas de disección (citológicas), material odontológico vario, instrumentos para trabajar la madera, punzones de plástico y madera, lijas, brochas, cepillos, pinceles (todos ellos de diferentes números, o sea, tamaños, tipos y durezas de las cerdas), lápices, portaminas y brochas de fibra de vidrio, escalpelos, espátulas inoxidables, bien para batir o modelar escayola, hipodérmicas, cordeles, zinc... y un larguísimo etcétera. En lo que a recipientes se refiere contaremos también con buen número de ellos fabricados en vidrio, porcelana y plástico. Estos serán por ejemplo ensaladeras de diferentes tamaños y tipos, vasos de precipitados, probetas, morteros, fuentes, baldes de plástico, tanques de desalación tanto para cerámica como hierro, recipientes herméticos para la basura, palanganas para el lavado de las piezas, cazuelas... El material en que se encuentran fabricados será del tipo específico a cada necesidad. No deberemos olvidar recipientes tan elementales e imprescindibles como los embudos, las botellas de cristal topacio o bien los recipientes de plástico de cierre hermético.

- A veces, debido a cuestiones de tipo económico, o bien ausencia de profesionales, valor de las piezas, rapidez en la ejecución de su tratamiento de conservación y/o restauración, etc... nos es necesario solucionar obligadamente toda una serie de problemas que entrarían en otros campos de trabajo. Así, el tallado de la madera o el modelado de la escayola, metacrilato de metilo... (que suelen acompañar a los trabajos de Conservación y Restauración) con fines tan diversos como pueda ser el fabricar una peana de exposición o cualquier otro tipo de soporte, por señalar tan solo un par de ejemplos entre una gama variadísima de necesidades. Un armario bien surtido de herramientas todas ellas muy comunes, nos pueden sacar de más de mil y un apuros cotidianos o situaciones extremas: tenazas, martillos de metal, goma y/o teflón, alicates, punzones, sierras para madera y metal, seguetas, soldador eléctrico... clavos, madera, alambres de diferentes diámetros, tornillos, tuercas... Aparentemente puede quizás sorprender o dar impresión de escasa importancia el contar con un receptáculo donde vayamos almacenando todo el sobrante de los trabajos de este tipo que vayamos realizando. Tampoco es convertir el lugar en un auténtico cajón de sastre; recortes, sobrantes de todo tipo, objetos mecánicos desechados por cualquier motivo o a medio terminar, etc... se dispondrán en un lugar específico al efecto. Con el paso del tiempo y la experiencia adquirida no sólo se probarán sus ventajas, sino que nuestro almacén se verá incrementado progresivamente y ciertas necesidades cotidianas se verán rápidamente solucionadas.

- El apartado que trata el tema de los productos químicos es quizá el área más delicada de entre las que componen nuestro laboratorio. Un alto porcentaje entre los tratamientos de Conservación aplicados hoy día a los objetos arqueológicos, están basados en la actualización de una gama cada vez más amplia de productos. Desde naturales hasta los de índole acrílica, son éstos los responsables de solucionar todos los problemas que diariamente se nos presentan, y que resultan inherentes a la propia materia de los objetos así como también al edafosistema que los circundó durante cientos o miles de años.

Desde la eliminación de las más duras corrosiones y costras, sales insolubles, manchas... inhibición (anticorrosión) y limpieza, pegado, capas de protección, reintegraciones de forma y hasta de color, etc... nuestra lista será confeccionada en base a las necesidades más urgentes y que obligadamente será de nuevo extensa. Ácidos (Oxálico, Nítrico, Fórmico...), 
disolventes (Hidrocarburos Aromáticos tales como el Xileno, Tolueno, Benceno), adhesivos termoplásticos (Imedio, Uhu, Pritt...) y termoendurecibles (resinas Epoxídicas), consolidantes de todo tipo (Primal AC-33, Paraloid B-72, B-48N y B-76, Bedacryl 122X...), bases (Hidróxido de Sodio, Sulfito de Sodio...), detergentes neutros (Napol, Lissapol-N...) y un muy largo etcétera. Todo lo relacionado con pigmentos, barnices y ceras protectoras (abeja, carnauba, microcristalina...), desmoldeantes, rellenadores (mastics), productos para la reconstrucción (escayola, Araldit, madera...), fungicidas (Xilamón, Benzoato de Sodio, Fenol, Timol... y sus derivados) etc..., deberán - o deberían- estar ineludiblemente presentes para llevar a cabo los trabajos con las máximas garantías de rigor, eficacia y estabilidad (Clypesdale, 1982).

Un almacén que asegure una perfecta estanqueidad será el mejor lugar para almacenar todo este cúmulo de material químico, tan numeroso como perjudicial y a la vez de alto riesgo. Estará perfectamente indicado tanto su situación y condición como lo que contiene en base a la normativa internacional de señalizaciones. En estanterías adosadas a la pared fabricadas en vidrio, gres antiácido o mismamente polietileno inerte, ordenadamente se dispondrán todos los productos perfectamente etiquetados de forma clara. Será un lugar fresco y ventilado. Por seguridad sería necesaria la instalación de un extractor de aire que pondremos a funcionar antes de acceder al interior, con la finalidad de que expulse cualquier tipo de vapor allí retenido por emanación. También procuraríamos situar rejillas a nivel del suelo -al igual que en el laboratorio-, pues como los disolventes pesan más que el aire descienden, y si no tuvieran salida al exterior permanecerían allí con riesgo de ulteriores peligros. Un detector de llamas, térmico o de humos, como es natural también será imprescindible. Poseerá un suelo antideslizante. La puerta estará impregnada de un producto ignífugo y a ser posible las paredes tendrán un recubrimiento interno. De esta manera en caso de incendio y tras su detección, el fuego permanecerá allí encerrado durante ese siempre precioso lapso de tiempo durante el cual puede dar lugar a su extinción o bien a ponernos a salvo. Podríamos evitar de esta forma su propagación al resto del edificio.

- Los análisis físico-químicos que sobre las siempre diferentes materias degradantes y/o degradadas deberían realizarse resultan un complemento imprescindible (CABRERA ORTI, 1994) (Gómez González, 1994). No obstante el acceder a una Difracción de Rayos X, Microscopía Electrónica de Barrido (S.E.M), etc... en definitiva el acceso a la más moderna tecnología analítica, es hoy por hoy no solamente muy difícil si no que muchas veces imposible. Los favores mediante la amistad y/o la comprensión de los investigadores-encargados en los centros especializados donde este tipo de analítica es común, suelen sacarnos de diversos apuros aunque no siempre todos los que fuesen necesarios ni mucho menos los que desearíamos.

Dentro de lo que entraña un laboratorio y su montaje en el sentido genérico del trabajo, pero restringiéndonos una vez más a la especialización en trabajos de arqueología, nos es posible distinguir varios tipos diferentes. No cabe duda que si lo destinamos a la conservación y restauración de objetos recuperados en el mar, los problemas presentados por estas piezas son de especial dificultad. En función de la estabilidad adquirida por cualquier pieza acondicionada por los siglos al ecosistema agua (incluida entre los restos de un pecio por 
ejemplo), la consecución de su equilibrio en el ecosistema aire resulta mucho más laborioso y económicamente caro que si dichos objetos hubieran sido extraídos bajo la tierra. El instrumental necesario es de gran volumen, necesita un cuidadoso mantenimiento, y su utilización es también económicamente costosa. Por otra parte el problema se ve acrecentado por el gran volumen de hallazgos que suelen llegar a contabilizarse, y que por consiguiente han de ser tratados (Pearson, 1987).

- En lo que concierne al control climático (Gürchen, 1984) del centro cuyos fondos custodia nuestro laboratorio cara a su conservación, es otra de las cruciales tareas a desarrollar y que muy pocas veces se controla dada su extrema dificultad en unos casos, o bien lo tedioso que supone este tipo de trabajo. No es la primera (y desgraciadamente no creemos que la última) vez que al visitar un centro museológico, hemos observado que del instrumental de medición hace meses que no se han retirado ni cambiado las hojas de registro ${ }^{6}$.

Como es natural, primeramente hemos de contar con el instrumental preciso para las mediciones (termohigrómetros, termohigrógrafos, luxómetros y ultravímetros) (HERRáEZ Y RODRIGUEz LORITE, 1989), según el esquema previo que hayamos realizado sobre el proyecto de control climático. Con posterioridad trazaremos un plan de actuación que como mínimo abarque un margen temporal de varios años en las diferentes áreas del edificio. Los parámetros ambientales de humedad relativa y absoluta, temperatura así como intensidad lumínica (grados Lux) e incidencia de rayos ultravioleta (UV), etc... serán tomados de forma diaria o bien por semanas según sea el sistema de registro de cada aparato medidor. Estos datos necesitarán ser contrastados con los reunidos a lo largo del tiempo que hayamos establecido para nuestro estudio y con los tomados del microclima ambiental que rodea al edificio. Estos podrán ser obtenidos bien por nosotros o aún mejor y de forma más fidedigna, en el centro meteorológico de cada área poblacional donde se halle ubicado el museo.

Todo ello tiene su razón de ser ya que cualquier edificio al igual que cualquier ser viviente, se encuentra sometido a la acción de los agentes externos tales como la luz, la lluvia, el viento, etc... Por lo tanto los edificios (continente) serán quienes hagan variar la humedad relativa y la temperatura de una determinada construcción, y por ende lo que ella encierre (contenido). Los drenajes, las canalizaciones, etc... son excelentes aislantes del agua y los parámetros ambientales dejan sentir de forma acusada la influencia de esta última, desde el mismo momento de su inexistencia, o bien por hallarse en estado defectuoso. Por contra, su correcta instalación puede llegar a ser definitiva en un lugar afectado, pudiendo llegar a eliminarse los problemas de una manera definitiva.

\footnotetext{
"Se están empezando a imponer cada vez con más fuerza los detectores que de forma automática envian los datos de humedad y temperatura en períodos de tiempo preestablecidos por el especialista hasta un ordenador-receptor. Este almacena los datos y un programa los ordena y nos ofrece todo tipo de resultados estadisticos de forma inmediata, sin la pérdida de tiempo que supone el introducir los parámetros uno a uno manualmente, conformar o comprar un programa específico, etc... (PORTA, 1992). Como siempre el principal problema, no sabemos si momentáneo, es su elevado precio.
} 
Aislantes térmicos si el recinto está junto al tejado del edificio, aislantes contra la humedad si los muros son de piedra o bien materiales herméticos si las ventanas no cierran en condiciones, etc... Son aspectos que han de tenerse necesariamente en cuenta antes de la construcción, si el edificio (y por lo tanto el laboratorio) es de nueva planta, o bien si ha sido transformado en caso de reutilización de un edificio más antiguo como vimos antes. Sea como fuere necesitaremos de un estudio climático (termohigrógrafos, observaciones directas, etc...), en función de los objetos a custodiar y con el fin de adecuar el microclima. En definitiva, conseguir unos parámetros estables donde las variaciones de humedad relativa y temperatura sean lo más adecuadas que nos sea posible, teniendo siempre en cuenta el clima ambiente que reina alrededor del edificio museístico es siempre cambiante por naturaleza. No obstante anticipamos la extrema dificultad que supone el sanear adecuadamente un edificio en lo que a humedad se refiere, y estabilizar su temperatura ambiente.

El museo frecuentemente recibe lotes de objetos de tan diversa procedencia geográfica como materia constitutiva, y que forman el alma-mater de toda exposición temporal. Los profesionales del laboratorio desde el momento que las piezas ingresan en el edificio han de establecer un rígido control sobre ellas tanto físico como ambiental, y según el plan preestablecido entre ellos, la dirección del centro y los encargados de la entidad o entidades que efectúan los préstamos. Múltiples y muy variados son los aspectos a tener en cuenta y nada fácil la tarea (CARreras y Tarrago et alii., 1991) (Herráez y Rodríguez Lorite, 1991). En este sentido la Exposición Universal de Sevilla-92 construyó un campo abonado en el aprendizaje en intervenciones de auténtica urgencia, con momentos muchas veces difíciles -y sumamente comprometidos- que pusieron a prueba la capacidad técnica y resolutiva de nuestro país y sus profesionales.

\section{LOS DIFERENTES ASPECTOS DEL TRABAJO}

Diariamente el profesional ha de enfrentarse en su lugar de trabajo con todo un ingente cúmulo de objetos a tratar. Por otra parte también deberá atender a todo un sinfin de aspectos que procurará no dejar de lado para que el ritmo del laboratorio no se vea alterado y el trabajo no se acumule. Son ejemplos de esto que venimos diciendo: la compra de bibliografía (investigación y tratamientos actualizados), catálogo con precios actualizados de productos e instrumental diverso, realización de presupuestos, extracciones in situ (FERNáNDEZ IBÁNEz, 1990), cuidado de los parámetros ambientales tanto del laboratorio como -y sobre todo- de los almacenes de material, salas de exposición y a ser posible el edificio en general, exposiciones temporales, etc... En definitiva, sin llegar a ser un sistema de producción en masa, finalizar el ejercicio anual con unos resultados apreciables, científicamente aceptables y que sean el reflejo de un sistema de trabajo eficaz.

- En lo que respecta al trabajo de Conservación y Restauración en sí mismo, se procurará llevar a cabo siempre mediante personal especializado y cualificado que posea unos conocimientos y una experiencia responsable. Es la única forma que los trabajos conlleven las máximas garantías. Si bien es cierto que en principio no entrábamos en el tema de 
las titulaciones 7 , lo cierto es que con respecto a otras disciplinas su acceso se encuentra sumamente hermético, que para nuestro caso concreto obligadamente deberemos optar por los profesionales debidamente titulados.

- Para ello el primer paso a dar será la planificación del trabajo sobre los objetos a intervenir. Estará englobada dentro de los objetivos que el museo se ha propuesto desde un principio. La teoría dicta o debería dictar que los primeros tratamientos deberán ser aplicados a las piezas en peor estado de conservación. Por ejemplo, los metales, y dentro de ellos los objetos confeccionados en hierro, tendrán absoluta prioridad o bien los objetos de tipo orgánico. Pero debemos tener en cuenta que un museo es un ente vivo y dinámico en constante evolución y cambio, o al menos así debería ser. Esto debería ser llevado a cabo no solo con los objetos almacenados de antiguo sino también con los de nueva adquisición ya sea mediante compra, donación o bien procedentes de las diversas campañas de excavación arqueológica que anualmente se realizan. Hablamos de los parámetros ambientales de humedad relativa y temperatura, a los que ya sobradamente hemos hecho referencia y que en definitiva son los que fundamentalmente (por lógica existen otros como la polución, hacinamiento, microorganismos...) conforman el ecosistema museable, donde vivirán y tendrán que ser conservados tales objetos para el futuro. Si no queremos enfrentarnos a su irremediable destrucción.

A este respecto hemos de hacer una necesaria referencia al denominado Módulo de

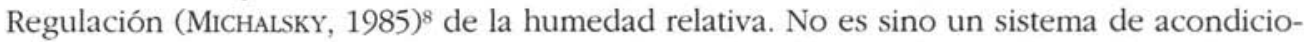
namiento para las vitrinas de exposición mediante el cual lograr el microclima adecuado para con las diferentes materias constituyentes de los objetos que son exhibidos en nuestros actuales museos. Consta en principio de un módulo de mando situado en las áreas de control del edificio y mediante el cual se controla la humedad relativa, temperatura, filtrado de partículas, etc... que entran en las vitrinas y se ponen en contacto con los objetos a través de un chorro de aire regulado y puro. Este aire controlado, que es el que establece el microclima idóneo, se evacúa por las rejillas existentes entre los cristales. Quizá lo más complicado y de lo cual se necesita una planificación previa, es todo el sistema o red de tuberías con diámetros de 1-2 y 3-4 cms. que se necesita para la distribución del flujo de aire.

Aunque resulta complicado, sobre todo si quisiéramos instalarlo en un museo de vieja planta, la verdad es que hoy por hoy creemos que puede suponer el único sistema eficaz para regular el ambiente circundante. Somos conscientes de que es costoso, problemático, muchas veces con relativa eficacia... y un largo etcétera, sin embargo encontramos especial-

\footnotetext{
- Bajo la denominación de Conservadores-Restauradores y con el fin de evitar equívocos o malas interpretaciones, hago expresa referencia a los profesionales de la Conservación y la Restauración. Hasta hace unos años se venían denominando como Restauradores; de materiales arqueológicos, de pintura, etc... De hecho aún se sigue utilizando el término de forma algo más que coloquial. Empero la nueva titulación expedida en nuestro pais por las Escuelas Superiores de Conservación y Restauración de Bienes Culturales tras la renovación del plan de estudios proporcionan actualmente la titulación de Conservador-Restaurador en la especialidad a que corresponda (B.O.E. 18.II.1989 y 30.IX.1991).

${ }^{*}$ Si se desea obtener el conjunto de planos sobre este sistema de climatización, estos pueden llegar a ser adquiridos en el Canadian Institute de Ottawa, Canadá (1030, Innes Road).
} 
mente interesante cuando las colecciones que se exponen están compuestas de material delicado de tipo orgánico como textiles o papel por ejemplo. No debemos olvidar que cuando se cuidan al máximo los parámetros ambientales de humedad y temperatura, suele evitarse la intervención físico-química en la mayoría de los casos.

Otro sistema que desde hace poco tiempo ha llegado a nuestro país y aún no es demasiado conocido, es la conservación de los objetos mediante nitrógeno. Se basa en un arcón herméticamente cerrado (cámara climatizada) donde son depositados los objetos, después de lo cual se inyecta gas nitrógeno hasta lograr la saturación del volumen interior. Está asegurada la perfecta inalterabilidad de lo allí almacenado, durante el tiempo que deseemos dada la total inocuidad del gas. Aparte de su alto costo económico posee otro handicap, y es que siempre que deseemos abrir la cámara para disponer en su interior nuevas piezas o bien extraer éstas, será necesario expulsar el nitrógeno existente e inyectar nuevamente una vez el recipiente sea cerrado de nuevo. No obstante es un magnífico sistema que puede llegar a ser muy rentable y útil, siempre y cuando lo utilicemos de forma conveniente.

El instituto norteamericano Paul Getty ha desarrollado una vitrina totalmente estanca con el fin de conseguir un ambiente anóxico (libre de oxígeno) mediante nitrógeno. Su eficacia parece probada por la adición del producto denominado "Ageless" (GILBERG y GraTtAN, 1994), que reduce la cantidad de oxígeno a menos de 0'0001\%. El Museo Víctor Balaguer de Barcelona es uno de los lugares donde ha sido instalada con el fin de preservar las momias egipcias allí expuestas, dado que se encontraban en un muy delicado estado de conservación (AGNEW Y LEVIN, 1996, 18).

El sistema de eliminación del oxígeno residual que aún permanece en los ambientes a los que se adiciona un gas inerte como es el nitrógeno, se realiza mediante una forma de óxido de hierro no tóxico (Ageless) utilizado en la industria para el envasado de alimentos. Aún más recientemente se ha desarrollado la denominada "Célula de Barrido de Oxígeno", probada en receptáculos de pequeño tamaño $\left(1 \mathrm{~m}^{2}\right)$ como puede ser una vitrina donde previamente ha sido inyectado nitrógeno. Aún hay muchos problemas a resolver como es la eliminación de la humedad presente ${ }^{9}$, pero no cabe duda que nos hallamos aunque un nuevo y prometedor sistema (Gilbert y Grattan, 1996).

Como ya dijimos con anterioridad nuestro plan de trabajo deberá ser el ya trazado previamente, aunque contando con imprevistos tales como intervenciones in situ durante las campanas de excavación, los más variados problemas en los tratamientos aplicados con anterioridad, una simple tardanza en la recepción de pedidos o el tiempo invertido en la mejora de las operaciones. A veces estos motivos quizás nos hagan retrasar cuando no incumplir nuestros objetivos. No deberá ser siempre esto motivo de preocupación. Un aspecto importante que el profesional deberá tener en cuenta, es que el trabajo de ConservaciónRestauración nunca deberá convertirse en una cadena de producción. Se actuará de forma ágil. Más concretamente aún, sin prisa pero sin pausa. Llegados a este punto viene a colación

"Para lo cual introduciremos Gel de Sílice con indicador de Cobalto (LAFONTAINE, 1984) o bien Art Sorb en bolitas o bien en pliegos (SIX ALTOR 1991). 
una frase célebre del Dr. Gregorio Marañón: "La rapidez es una virtud. Engendra un vicio que es la prisa". Quien deberá mandar en todo momento deberá ser el propio objeto a conservar y/o restaurar. Deberá ser él quien nos diga qué es lo que le ocurre a través de nuestra experiencia y conocimientos, siendo estos mismos quienes nos propondrán la forma de actuación. O sea, paralizar los procesos de alteración y estabilizar su materia, en definitiva el tratamiento a aplicar. Todo esto es conseguido gracias al diálogo que el especialista establece con el objeto. Dicho diálogo se establece en base como es natural a un lenguaje que es conocido y compartido entre el objeto y el profesional que lo interviene. Es un leguaje carente de palabras pero que está ahí, aprendido diariamente en la escuela que hora tras hora y día tras día forja el oficio.

A nuestro entender, una de las facetas fundamentales en el correcto devenir de las actividades museológicas y que nunca deberemos dejar de lado es el correcto entendimiento entre los responsables de la dirección, arqueólogos, historiadores del arte, etnógrafos, etc... con los profesionales de la Conservación-Restauración (CHAVigner, 1993). Supone algo fundamental. La buena fe, el respeto profesional, la pluridisciplinariedad, la comprensión y en definitiva hasta la convivencia diaria serán cuestiones prioritarias. Por uno y otro aspecto cuando salen a aflorar temas que nada tienen que ver con lo que tratamos (cuestiones personales, profesionales, intereses, rangos...) se viene todo abajo o queda tan sumamente mutilado, que además de dar al traste con la planificación inicial, también el resto de objetivos quedan en la deriva más irreversible (J.P.S., 1987).

- A la hora del montaje del laboratorio tan importante como su dotación, situación o planificación será el contar con un lugar donde la seguridad de los objetos tanto física como ambiental, sean así mismo primordiales puntos a tener en cuenta. Para mayor seguridad durante los tratamientos de los objetos de especial valor, sería conveniente contar con una caja fuerte que podría tener inclusive alarma incorporada si deseásemos rizar el rizo, y apertura mediante fórmula. Ni que decir tiene que la combinación tan sólo debería obrar en poder del o de los conservadores-restauradores, jefes de sección y por supuesto de la dirección.

\section{LABORES COMPLEMENTARIAS}

Creemos también que es hora de hacer alusión al tan recurrido axioma de Cesare Brandi que incluyó en su conocido libro "Teoría del Restauro". La cosa cambió y los horizontes se abrieron cuando dicha obra fue recientemente traducida al espanol (C. BRANDI, 1988). Dicho axioma establece de manera muy acertada, caracterizando la concisión y agudeza de pensamiento del que fue su autor, que el trabajo de Conservación y Restauración supone un momento irrepetible, un momento metodológico utilizando sus palabras. Durante este momento que puede suponer minutos, horas o bien días y sobre todo durante y después de los primeros pasos de la limpieza llevada a cabo en los objetos, nos encontramos en condiciones de escudrinar y conocer la obra que tenemos ante nosotros como nunca antes se hubo hecho. Lo más probable también es que este momento no vuelva y podemos argumentar el porqué con un par de razonamientos. El primero y fundamental es por la multitud de piezas existentes y por las que demasiado pronto suele perder interés el investigador. El 
segundo, por no proceder de manera continua a reversibilizar los tratamientos aplicados a los objetos, debido fundamentalmente a lo que de alteración innecesaria supondría. No obstante, debemos tener en cuenta que los diferentes pasos dados sobre los objetos intervenidos debido a su estado de conservación, no dejan nunca a estos objetos tal y como se encontraban tras la limpieza preliminar.

Abundantes serían los ejemplos sobre lo dicho anteriormente. Utilizando otro orden de materias sería la firma del artista en un lugar imprevisible de su cuadro, o bien cierta hueIla que lo identifica tal como cartas o papeles fechados que se utilizan como adhesivos (fragmentos de diarios), y que nos dicen la época de una determinada intervención reparadora, correcciones o arrepentimientos del artista. Huellas de los bocetos, técnicas de fabricación y un larguísimo etcétera, casi tanto como número de obras.

- Tema harto delicado y sobre el cual nunca nos pondremos totalmente de acuerdo por naturaleza, es el que comprende los tan traídos y llevados criterios de actuación o de intervención.

La definición de criterio, tan variada como profesionales existen, en pocas palabras se definiría como aquellas pautas y/o normas que en principio y abarcando un sin fin de aspectos teóricos (respeto histórico-artístico, estético...), intentan ser extrapoladas a la obra a tratar mediante la aplicación de toda una larga serie de técnicas con las que hoy es posible contar. En ellos se refleja también el Código Deontológico de la profesión (ICom, 1990). No se trata de los medios técnicos con los que acometer los trabajos, sino más bien la forma moral de llevarlos a cabo para no intervenir (o más bien intervenir lo menos posible) sobre los datos históricos -materiales o no-, y mucho menos alterarlos. Se busca en definitiva la inocuidad en la intervención dentro de todos los aspectos posibles e imaginables.

En la generalidad de estos criterios podemos entender dos tipos diferentes, que aunque resultaría muy difícil establecer fronteras entre ellas existen y nada mejor para demostrarlo que las controversias entre profesionales. El primero de los tipos propuestos agruparía aquellas normas aceptadas de manera universal por todos y cada uno de los profesionales (Amitrano Bruno, 1985) (CASAdo Hernández, 1994), debido a lo cual y en principio no plantean problema alguno. Serían ejemplos de lo dicho la no falsificación en las intervenciones e inocuidad de éstas, reversibilidad de los tratamientos (aunque la reversibilidad al 100\% como tal es imposible) (Mourey, 1987, 75), etc... El otro tipo lo formarían todos los criterios que nacidos de los anteriores intentan completar y complementar a aquellos, pero esta vez con un cierto matiz personal. Nos referimos a que todas estas ideas son compartidas por un grupo allegado de personas o bien de manera particular, de tal forma que durante las reuniones científicas siempre hacen brotar enriquecedoras discusiones y la exposición de puntos de vista enfrentados. Ello supone que nunca serán de aplicación universal entre profesionales. De todas formas no crean serios problemas ya que la mayoría de las veces y entre la multitud de aspectos que pueden llegar a tenerse en cuenta, el respeto por los Bienes Culturales en general suele ser la norma imperante.

- Una faceta extremadamente importante que solo últimamente comienza a llevarse a cabo de forma generalizada en los laboratorios, es la denominada Ficha de Registro de los Tratamientos o simplemente ficha de la pieza intervenida. En términos comparativos 
sería el historial clínico de cada objeto. En ella se refleja o se debería reflejar el estado en el que dicho objeto ingresa en el laboratorio, los avatares acaecidos hasta entonces si es posible llegarlos a conocer, la totalidad de nuestras intervenciones y, muy importante, todo lo que hayamos observado por insignificante que nos parezca. También aquello que no comprendamos o identifiquemos, los pasos dados, el instrumental utilizado, los productos empleados y sus concentraciones, etc...

Las funciones de esta ficha son mucho más importantes y necesarias de lo que en un principio podamos imaginar. El robo, la pérdida o destrucción del objeto pueden llegar a ser realidades. Así mismo lo puede llegar a ser también la ficha-inventario del museo correspondiente, por lo que con ésta tendremos un duplicado. Otra de las indudables ventajas que posee es de servir de registro sobre todos aquellos productos u operaciones realizadas. En un futuro más o menos lejano, la reversibilidad de todo o parte de lo realizado o introducido en una pieza puede ser una operación necesaria según lo ya visto líneas atrás. El registro de datos no conocidos, tanto huellas de índole histórica, tecnológica, etc... como también aspectos y observaciones diversas sobre las alteraciones, son otros aspectos que la hacen a todas luces justificable.

El sistema utilizado por cada profesional suele ser diferente, aunque existan grandes concomitancias. Ahondando aún más en detalle, la ficha-tipo se compondría de cuatro partes. La primera donde se registren aspectos tales como el lugar de procedencia, datos técnicos específicos: medidas, descripción, fecha de inicio y fin de los trabajos, restaurador... La segunda consta de dos apartados, el primero donde se describe su aspecto a la llegada al laboratorio (estado de conservación), y el segundo, el tratamiento que ha sido llevado a cabo, las observaciones pertinentes y la bibliografía. Todo el corpus de fotografías, esquemas y dibujos obtenidos antes, durante y después de los trabajos se almacenarán en el tercer apartado. Y finalmente el cuarto y último lo engloban las observaciones efectuadas en cada período de tiempo variable y con posterioridad al tratamiento aplicado. Esta última faceta es bastante importante y generalmente las fichas existentes no lo suele reflejar. Es común el que las piezas tratadas sean comparadas con enfermos que tras su cura, deberán ser estrechamente vigilados en previsión de posibles recaídas. A los objetos arqueológicos les ocurre algo parecido. Una vez que son expuestos en las vitrinas al público o bien se guardan en los almacenes del museo, han de ser necesaria e inexorablemente vigilados. Múltiples aspectos relacionados con el ecosistema circundante pueden ser causa de alteraciones, y ahí debemos estar nosotros para solucionarlo o aún mejor, evitarlo.

- Dentro de la importancia y responsabilidad que supone el estar a cargo de la Conservación y Restauración del Patrimonio en general (y arqueológico en este caso específico), la investigación es uno de los aspectos más cruciales y a la vez más desatendidos. Podemos ver justificado el hecho por el cual durante los primeros balbuceos de la disciplina la investigación -si así podemos denominarla- deambulaba un tanto desorientada; varios fueron los motivos. Ante la ingente cantidad de objetos a "salvar" lo más crucial era parar como fuese los procesos destructores. El binomio acierto-error con respecto a la observación de los productos empleados un poco al azar (CARBallo, 1927), fue de hecho lo único que se podía hacer en un país como España con un rico e ingente Patrimonio, carente de antecedentes, con múltiples problemas de todo tipo y demasiado autosuficiente... No obstante y 
salvo excepciones, tales actuaciones eran ya de por sí investigación. Estas, en la mayoría de las ocasiones, fueron publicadas en artículos de revista, pero su número total nunca llegó a alcanzar la docena (FERNÁNDEZ IBÁṄEZ, 1986b y c). Aún así y según lo visto, los casos fueron contados, sin entrar ya en las actuaciones de "los manitas" que en todos los lugares había, aunque habilidad era de lo que más carecían. Sin ánimo de crítica destructiva, las actuaciones de estas personas acuciaron toda una serie de problemas que hoy nos es posible evaluar. A raíz de lo experimentado allende nuestras fronteras y refiriéndonos fundamentalmente al Museo Británico de Londres, muy poco a poco se fue creando un poso que germinó en el año 1961 con la creación del Instituto Central de Conservación y Restauración (I.C.C.R.), lo que hoy es el I.P.H.E. (Instituto del Patrimonio Histórico Español).

Así las cosas y ya a las puertas del siglo XXI abogamos por que hoy se puede y se debe investigar, aunque a decir verdad de forma precaria. Los problemas que diariamente nos plantean las diferentes materias distan mucho de estar radicalmente solucionados. Lo joven de la intención supone de momento un handicap que no obstante se va paliando; el tiempo nos dará o no la razón.

En este sentido un aspecto importante y complementario a los tratamientos que ahora comienza a ser abordado de forma eficaz, es el intento de conocer lo más profundamente posible los procesos de alteración. Todas y cada una de las materias de que están compuestos los Bienes Culturales, salvando muy contadas excepciones, es por todos bien conocido que habitualmente sufren un envejecimiento que en definitiva supone una alteración y/o transformación a través del tiempo, cuyos efectos físicos y químicos serán más o menos acusados en función de múltiples factores. En la generalidad se puede afirmar que es producto del ecosistema circundante al propio objeto y la composición de materia constitutiva. Dijimos líneas atrás que durante el nacimiento de esta disciplina y en base a la pura eficacia, la preocupación fundamental durante estos primeros tiempos fue la búsqueda de cómo poder frenar las alteraciones. Es una situación que pese a no carecer de lógica ha durado hasta nuestros días. Sin embargo hoy ya contamos con suficiente infraestructura analítica como para acometer el siguiente paso, pero sin abandonar otros no menos importantes y necesarios. Es un tema que en ciertos aspectos permanece tan de lado que urge saber de forma absoluta hacia dónde nos puede llevar. En principio, a mejorar los tratamientos aplicados o bien crear otros nuevos. Cabe la posibilidad de que pueda ser utilizado en algo tan importante como puede ser el desestimar los ya conocidos.

- En otro orden de cuestiones nos quedan aún por tratar dos puntos importantes. El primero de ellos se refiere a contar con una biblioteca donde podamos consultar nuestras dudas y apuntalar nuestra labor investigadora. Dicha biblioteca la deberemos reunir por dos vias diferentes, una la compra de libros y monografias y otra -no siempre viable en todos los centros museísticos- mediante el intercambio de publicaciones científicas. Como decíamos esta última no es abordable por la totalidad de los museos o laboratorios ya que no siempre éstos cuentan con una publicación propia. Esta faceta bibliográfica que consideramos fundamental, nunca podrá llevarse a cabo de manera completa mediante la compra de publicaciones de forma personal por parte de los profesionales. El encarecimiento de la prensa científica en estos últimos años, sumado a la amplísima variedad y cantidad de publicaciones hoy en el mercado, hace imposible desde todo punto de vista su adquisición mediante la forma 
indicada. Supone además un serio handicap a la hora de ponerse al día en cuanto a los últimos descubrimientos se refiere.

Aunque solo sea a vuelapluma en este apartado hemos de dejar constancia de un apartado en el laboratorio que pocos lugares poseen, y es que junto a la biblioteca por ejemplo sea instalado un despacho. Desde recibir a técnicos, realizar las fichas apoyados por un ordenador, realizar consultas, presupuestos, proyectos, archivado de documentación escrita y de cualquier otro tipo... y un sin fin de actividades ajenas todas ellas a las mesas donde se desarrolla el trabajo puramente manual. Verdaderamente no es un lugar imprescindible. Es más algunos pensarán que totalmente prescindible, pero su utilidad es evidente y nunca se valora hasta que no se realizan ciertas labores sobre una mesa de despacho

- Esto no es óbice -y nunca lo deberá ser- para que nuestro laboratorio también sirva como centro de formación, lugar de toma de experiencia y complemento de los estudiantes que deseen realizar prácticas laborales. Ciertamente que el laboratorio nunca deberá llegar a convertirse en un centro de enseñanza, ya que para ello cumplen perfectamente esta función las distintas Escuelas Superiores. Pero no obstante, durante algunos meses y previa selección, se podría llevar a cabo una instrucción que sirva de complemento práctico y suma de conocimientos a los asistentes. Y que a la vez sirva también de cierta ayuda en determinados trabajos del centro. Se deberá dar por supuesto que las personas admitidas deberán poseer unos conocimientos cuyo nivel deberán evaluar el o los responsables del laboratorio en colaboración con la dirección del centro museístico.

- No desearíamos finalizar este trabajo, sin hacer alusión a un aspecto que básicamente nunca ha sido tratado, y contadas veces llevado a la práctica. El acercamiento al público en general por parte de los conservadores-restauradores; o sea la faceta pedagógica del laboratorio. Parte en principio de dos problemas, que no siempre han resultado insalvables (Molina Carrión y Santiago Pérez, 1988). Los laboratorios de trabajo se encuentran siempre situados en las áreas de servicios de cada museo, donde por razones obvias el público no accede. Sin embargo no debemos olvidar que el museo como centro destinado a la conservación, investigación y fundamentalmente a la enseñanza (entre otras múltiples facetas) debe o debería abordar tales aspectos desde una perspectiva atrayente; cómo trabaja y de qué se vale para desarrollar su actividad diaria. El hermetismo que la mayoría de las veces de forma involuntaria envuelve a tales centros, crea una curiosidad no siempre bien sana, oculta valiosa información a nivel pedagógico, y en general no ayuda en nada a crear vocaciones, o simplemente contribuye a la ignorancia de la mayoría. Otro modo de enfoque sería aquel que debe justificar ante la sociedad (de quien al fin y al cabo son -y somos- herederos directos con respecto al Patrimonio), las labores de custodia y conservación que se llevan a cabo.

Múltiples son o bien han sido en el mejor de los casos, los sistemas empleados. Las publicaciones (más bien sumamente escasa o escritas en idiomas tan científicos como ininteligibles para los no iniciados) o bien los cursillos y conferencias por exponer tres simples ejemplos, han llegado a ser las soluciones más cómodas que se han adoptado. En otros lugares el laboratorio situado junto a las salas de exposición y mediante una pared acristalada, servía al público para ver el trabajo como era desarrollado por los especialistas mientras efectuaban la visita. Indudablemente tampoco esta es la solución por las comodidades que sub- 
yacen a un trabajo como este (IMHOF, 1980, 48-51). Pero mismamente, incomodidad que también subyace con respecto a otras actividades que diariamente se desarrollan en los centros museísticos, si adoptásemos tal sistema de muestra: áreas de fotografía, investigación, etc...

La solución en principio no es fácil, pero deberemos encontrar vías de solución. Manuales fácilmente comprensibles para el público en general en cuanto al lenguaje utilizado, es una faceta que en España ya se ha llevado ha cabo en más de una ocasión. No obstante creemos que la mejor forma de trasmitir, se encuentra en el manejo y en el "juego". Esto es, tal y como se llevó a cabo en la exposición sobre "Climatología y Conservación en los Museos". Si se intenta hacer comprender qué es, para qué sirve y cómo funciona un luxómetro el mejor procedimiento no es exponer el aparato. Por ejemplo, si en una vitrina oscura instalamos uno de estos aparatos junto a bombillas de diferentes tipos (incandescentes, tungsteno...), colores e intensidades y que además pueden ser encendidas desde el exterior, los visitantes tras las explicaciones correspondientes pueden accionar los mandos. De esta manera práctica comprenderán muchísimo mejor la problemática y el peligro de la luz sobre los objetos. Una vitrina anexa con ejemplos prácticos, plasmados mediante varios objetos afectados debido al problema lumínico y junto a otros perfectamente conservados, indudablemente supone un complemento idóneo de comprensión.

Otro método serían los videos que siempre suelen escasear en los departamentos de publicaciones. Eso sí, a bajo coste al igual que las publicaciones. Conseguiremos peores resultados si la edición es de lujo e inalcanzable al bolsillo del ciudadano medio que si no existe. La persona verdaderamente interesada, volverá a su casa con las manos vacías además de con un gran sinsabor, olvidándose de lo que aprendió horas antes.

Los cursillos a "bajo nivel" (casi inexistentes), e inclusive el introducir aspectos específicos sobre la conservación durante las charlas destinadas a los profesores de EGB y BUP, es otra de las posibles alternativas.

Quizás la más idónea de las soluciones y a la vez complementaria a lo ya expuesto, sería la visita a los lugares específicos. Tales visitas serían guiadas previa petición de fecha y tan sólo por ejemplo durante un día a la semana, pero siempre en pequeños grupos. De esta buena intención -si queremos ser totalmente objetivos- pueden derivar varios inconvenientes. El primero sería la molestia en los lugares de trabajo, sobre todo si estos son de reducidas dimensiones, mas no lo creemos un serio inconveniente. La segunda y más peligrosa estaría relacionada con la seguridad. En el grupo de visitantes pueden llegar a infiltrarse cierto tipo de personas, que lo único que persigan sea hacerse una idea lo más fiel posible del edificio y sus accesos, ventanas, sistemas de alarma, etc... con vistas a ciertas actividades de robo o bien en el peor de los casos y con idénticas intenciones ocultarse en lugares recónditos para que una vez este clausurado el museo, dejar libre acceso a compañeros que aguardan en el exterior del edificio (Hernández Hernández, 1994, 252-260) (Tillotson, 1980). 


\section{CONCLUSIÓN}

Una vez analizados en detalle los problemas que conlleva el difícil mundo de la Conservación y Restauración de las diferentes materias constituyente fundamental de los Bienes Culturales en general y arqueológicos en nuestro caso específico, la principal conclusión viene dada casi por sí sola. Es absolutamente imprescindible ya no solamente crear laboratorios de Conservación y Restauración, sino que estos se encuentren convenientemente equipados. El contar tan sólo con material de prevención no es suficiente, ya que debido a su total inoperancia debida a la imposibilidad de controlar edificios "continentes", su rentabilidad a todos los niveles precaria. De esta manera no sólo tendremos solventados los problemas que en principio creíamos solucionados, sino también la adición de nuevos casos al ritmo de la investigación y la necesidad de un desembolso económico extra, siempre de última hora y económicamente caro que hace difícil su adquisición. Además será necesario un mayor número de personal cualificado si el trabajo se desea llevar a cabo con agilidad.

Los laboratorios en sí no son ni deberían ser nunca lugares donde hubiese una excesiva rigidez laboral. Pensando en su eficacia y en la tan traída y llevada economía, verdadera espada de Damocles que a todos los lugares apunta, sobre todos los programas pesa dirigiendo todo tipo de empresa. Un centro de este tipo puede llegar a tener la flexibilidad suficiente como para poder tratar varios tipos de materiales. Sabido es que la Conservación y Restauración sólo es una así se trate de arqueología, pintura o etnografía por ejemplo. De esta manera por un poco más, el laboratorio puede ser destinado a trabajos de imaginería y arqueología, de etnografía y pintura o bien de escultura-arqueología-pintura entre otras posibles variaciones. Aunque naturalmente, también será necesario adquirir equipamiento a veces bien diferente según la obra y materia a conservar y/o restaurar.

Pueden ser centros piloto, como es el caso de un Instituto Regional (autonómico), y contar con varios tipos de laboratorios satélite. Uno por provincia en cada museo aunque también es posible (y tomando como ejemplo a la arqueología), un laboratorio de tipo itinerante o un local acondicionado cercano a los yacimientos en fase de excavación. Cada uno de estos se encontraría en correspondiente dependencia con el inmediato anterior. Pero no obstante esto hoy por hoy es una utopía. Más bien la cruda realidad es otra, y a veces malamente hemos de tender a la búsqueda de la máxima eficacia a base de precarios medios. Llegar a conseguir aunque sólo sea un lugar donde poder realizar todo este tipo de actuaciones es ya de por sí un triunfo.

Con posterioridad viene la segunda parte, que si la anterior es de por sí ya incompleta, la que ahora tratamos brevemente es en muchos aspectos inexistente. Englobaría los sistemas de seguridad personal de los trabajadores, y que irían desde aparatos de extinción de incendios, extractores... hasta almacenes para productos químicos. Así mismo también la planificación de los trabajos, el equipamiento necesario, la investigación y un largo etcétera ya visto en extensión. Aunque tratado aquí como segundo apartado, sin duda es uno de los principales, y el que verdaderamente hace funcionar todo el sistema de trabajo diario en las condiciones debidas. 


\section{BIBLIOGRAFÍA}

Agnew, N. y Levin, J. (1996): Adaptar la tecnología a la conservación, "Conservación. Boletín del G.I.C.” XI-3, pp. 16-18.

Amitrano Bruno, R. (1985): Evolución y desarrollo de los criterios de restauración de la antigïedad al panorama actual, "La Restauración en España", "Revista de Arqueología" 47, pp. 20-33.

Bfltran Lloris, M. (1994): Museo de Zaragoza. Memoria 1994 (I), "Boletín del Museo de Zaragoza" 13 , pp. 362-445.

Berdicou, M. Cl. (edit.) (1990): La Conservation en Archéologie, París.

Brandi, C. (1988): Teoría de la restauración, Madrid.

Cabrera Ortt, Ma . A. (1994): Los métodos de análisis fisico-químicos y la bistoria del arte, Granada.

Calvo, A. (1997): Conservación y Restauración. Materiales, Técnicas y Procedimientos. Barcelona

CARBAllo, J. (1927): Nuevo procedimiento para la conservación de osamentas fósiles, "Bastón de Mando Prehistórico Procedente de la Caverna de El Pendo (Santander)", Santander, pp. $45-51$.

Carreras y Tarrago, A., Pedragosa y García, N. y Pujol Álvarez, N. (1991): El papel del conservador-restaurador en el montaje de exposiciones temporales y/o itinerantes, "Actas del VII Congreso de Conservación de Bienes Culturales", Bilbao, pp. 53-64.

CASAdO Hernández, J. (1994): En torno a la conservación-restauración y sus criterios de actuación en arqueologia, "Actas del $\mathrm{X}^{\circ}$ Congreso de Conservación y Restauración de Bienes Culturales", Cuenca, pp. 127-135.

Chavignfr, F. (1993): Archeologi e restauratori, la regioni della collaborazione, "Archeologia, Recupero e Conservazione", Firenza, pp. 75-89.

Clydestale, A. (1982): Chemicals in conservation: A guide to possible bazards and safe use. Roma.

DAIFUKU, H. (1979): Instalación del laboratorio. Ejemplo de un programa de ayuda de la UNESCO a países de las regiones tropicales, "La Conservación de los Bienes Culturales", Paris ( $2^{3}$ edición), pp. 89-101.

FFRNÁNDEZ IBÁNEZ, C. (1986a): Una nueva experiencia en arqueología de campo. El laboratorio de conservación y restauración de las excavaciones romanas de Julióbriga (Reinosa, Cantabria), "Arqueología" 13, pp. 185-188.

FERNÁNDEZ IBÁṄEZ, C. (1986b): Bibliografía en lengua castellana sobre conservación y restauración de materiales arqueológicos, "Conclusiones y Ponencias del Vªngreso de Conservación y Restauración de Bines Culturales, Actas de VI Congreso de Conservación y Restauración de Bienes Culturales", Tarragona, pp. 351-360.

FERNÁNDEZ IBÁṄEZ, C. (1986c): Bibliografía en lengua castellana sobre conservación y restauración de materiales arqueológicos (II), "Actas de VI² Congreso de Conservación de Bienes Culturales", Tarragona, pp. 185-191. 
Fernández IbáÑez, C. (1987): Museos y conservación, "El Museo de Pontevedra" XLI, pp. 669682.

FERnÁNDEZ IbÁṄez, C. (1988): Los laboratorios de conservación en los museos arqueológicos, “Actas del X Congreso de Estudios Vascos", San Sebastián, pp. 469-471.

FERNÁNDEZ IBÁṄEZ, C. (1990): Recuperación y conservación del material arqueológico "in situ". Guia de campo, Santiago.

FERNÁNDEz IBÁÑEZ, C. (1993): Organización y funcionamiento del laboratorio de conservación y restauración, “Arqueología y Conservación”, Xinzo de Limia, pp. 117-129.

Fernández MARTínez, V.M. (1989): Teoría y método de la arqueología, Madrid.

Franco González, Mª̉ E. y Casares González, E. (1980): Investigación de los adhesivos empleados en la conservación en México, México D.F.

Gilberg, M. y Grattan, D.W. (1994): Oxygen-free storage using Ageless oxygen absorber, "Preventive Conservation", pp. 177-180.

GILBERG, M. y GRATTAN, D.W. (1996): A dynamic system for removing oxygen from air using an electrochemical cell, "Studies in Conservation" 41-3, pp. 183-186.

Guichen, G. DE (1984): Climat dans le musée, Roma.

Gómez González, Mª L. (1994): Examen científico aplicado a la conservación de obras de arte, Madrid.

Hernández Hernández, F. (1994): Manual de museología. Madrid.

Herráez, J.A. Y Rodríguez Lorite, M.A. (1989): Manual para el uso de aparatos y toma de datos de las condiciones ambientales de los museos, Madrid.

Herráez, J.A. Y Rodríguez LoRIte, M. A. (1991): Recomendaciones para el control de las condiciones ambientales en exposiciones temporales, Madrid.

HoDges, H. W. M. (1979): Instalación del laboratorio. Equipo y operaciones fundamentales, "La Conservación de los Bienes Culturales", Paris ( $2^{\mathrm{a}}$ edición), pp. 86-97.

Imhof, P. (1980): EL Museo Internacional de Relojería, en Le Chaux-de-Fonds, Suiza, "Museum" XXXII-1/2, pp. 45-53.

J.P.S. (1987): Le dialogue archeologue-conservateur-restaurateur "Conservation des Sites et du Mobilier Archéologiques", Firenze, pp. 110-111.

JOVER, A. (1989): Conservació y restauració dels objects arqueològics, "Excavacions Arqueològiques Subaquatiques a Cala Culip (I)", Girona, pp. 45-55.

JOVER, A. (1993): Extracción y tratamiento de objetos arqueológicos submarinos, "Arqueología y Conservación", Xinzo de Limia, pp. 73-85.

Lafontaine, R. H. (1984): Silica Gel, Ottawa.

Marín Baño, C. y Zambrano, L. C. (1995): Conservación preventiva. Actuaciones desarrolladas en el proyecto arqueológico "Nave Fenicia" de Mazarrón, "Cuadernos de Arqueología Marítima" 3, pp. 187-208.

MiCHALSKI, S. (1985): Un módulo de regulación de la bumedad relativa, "Museum" 146, pp. 85-88. 
Molina CARrión, M. y SANtiago Pérez, A. (1988): Conservación y restauración en el Puerto de Santa María, "Revista de Arqueología" 85, p. 60.

Mourey, W. (1987): La conservation des antiquites métalliques. De la fouille au musée, Draguignan.

Murdoch, L.D. (1978): A stainless steel treatment tank for the conservation of waterlogged uood, "Studies in Conservation" XXIII-1, pp. 69-75.

NORTH, N.A. (1987): Conservation of metals, "Conservation of Marine Archaeological Objects", Londres, pp. 207-252.

OrGan, R.M. (1968): Design for Scientific Conservation of Antiquities. Londres

ORGan, R.M. (1987): An adaptable compact modular bench, "Studies in Conservation" XXXII1, pp. 41-46.

PeARSON, C. (1984): La conservation du patrimoine subaquatique, "La Sauvegarde du Patrimoine Subaquatique", Paris, pp. 79-136.

Pinilla Pinilla, E. (1982): Los talleres de restauración en los museos. Criterios básicos, "Actas de la Primeras Jornadas del Patrimonio Histórico-Artístico”, Burgos, II, pp. 809-810.

PORTA, E. (1986): El conservador-restaurador: Una definición de la profesión, "Actas de VI Congreso de Conservación de Bienes Culturales", Tarragona, pp. 48-51.

PORTA, E. (1992): Los ordenadores y adquiridores de datos en las medidas climáticas de los museos, "Actas del $\mathrm{IX}^{2}$ Congreso de Conservación y Restauración de Bienes Culturales", Sevilla, pp. 764-767.

RINUY, A. Y SCHWEIZER, F. (1982): Application of the alkaline sulphite treatment to archaeological iron: A comparative studi of different desalation methods, "Conservation of Iron", Greenwich, pp. 44-49.

SLABCZYNSKI, S. (1964): Establishing a laboratory for restauration of paintings, "Museums Journal“ LXIV-1,

Tillotson, R. C. (1980): La seguridad en los museos, Madrid.

VEPREK, S. (1990): Die Behandlung archäologiscer Objekte aus Metall in einem Niederdruckplasma, "Restauro" XCVI-2, pp. 125-130.

ICOM (1990): Code de déontologie professionnelle, París.

Sin Autor (1991): Art-sorb, "Productos de Conservación. Boletín de Información" 2, Madrid, p. 1. 